\title{
Use of Satellite Images to map Flood Extension around the city of Saint Louis in the Senegal River Estuary
}

Aliou Dia, Jacob Loulou Kouame, Jean-Paul Rudant and Soulèye Wade.

\section{Introduction}

The traditional method of landsat satellite data combination and the gathering of important information made it possible to produce a Geographical Information System to monitor floods in the lower estuary of the Senegal River valley (Sandholt, I., Fog, B. \& Fensholt, R., 2001). This technical approach is a powerful tool for combining important information for a better comprehension of the floods and the characterization of surface qualities on the estuary. By way of a multi-temporal approach, the study team established the qualitative and quantitative impact of floods on the various geographical objects, a detailed cartography of the land use and the surfaces flooded in 1998 and 1999. The study undertaken in Saint Louis made it possible to consider surfaces flooded in 1999, and to understand the extent of these floods compared to those of 1998. The constitution of a tool of decision-making aid makes it possible to have information relating to the extent of the flood, the scope of flooded surfaces and to detect the more exposed zones in order to establish a hierarchical map according to the percentage of exposure to the risk of the geographical objects affected by the floods (populations), road infrastructures and tracks, medical and social infrastructures and perimeters of cultures (agriculture). 
When river water levels exceed 1.2 meters above mean sea level (MSL), flooding occurs in Saint-Louis (Gilif ${ }^{2}$, 2002). According to the measurements at Saint-Louis, this has occurred nine times since 1964. Since the barrage was constructed in 1985, this has only occurred three times.

\section{Spot Image Data}

The SPOT 4 images (1999, 2001 and 2002) were acquired from a project developed by University of Dakar in collaboration with University of Marne la Vallée (France).

Tableau 1: Available image for this study

\begin{tabular}{|lr|l|l|l|}
\hline Date & & Mode & Season & Observations \\
\hline \begin{tabular}{|lr}
23 \\
1999
\end{tabular} & 10 & XS 4 & Rainy & high floods \\
\hline $\begin{array}{l}31 \\
2001\end{array}$ & 10 & XS 4 & Rainy & low floods \\
\hline $\begin{array}{l}16 \\
2002\end{array}$ & 01 & Panchromatic & Dry & no floods \\
\hline & & & & \\
\hline
\end{tabular}

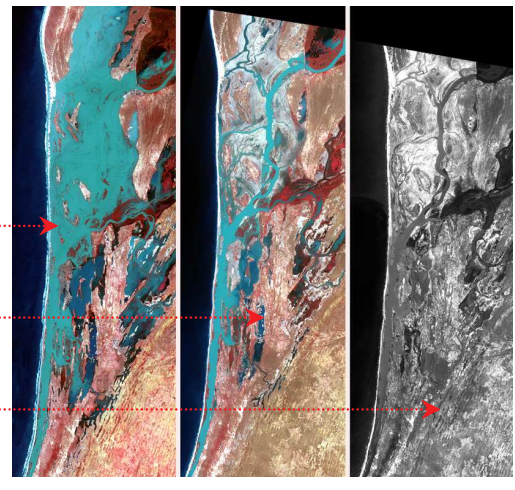

Figure 3: SPOT images

\section{View of flood extension in the estuary}

The satellite image below (figure 3) indicates the difference between the floods of 1999 and non-flood conditions. Unlike the normal floods, which cover large parts of the valley for several days or weeks during August to September 1999, the floods in 1999 lasted until mid-October in many areas, killing people and destroying roads, houses, crops, and other assets. 


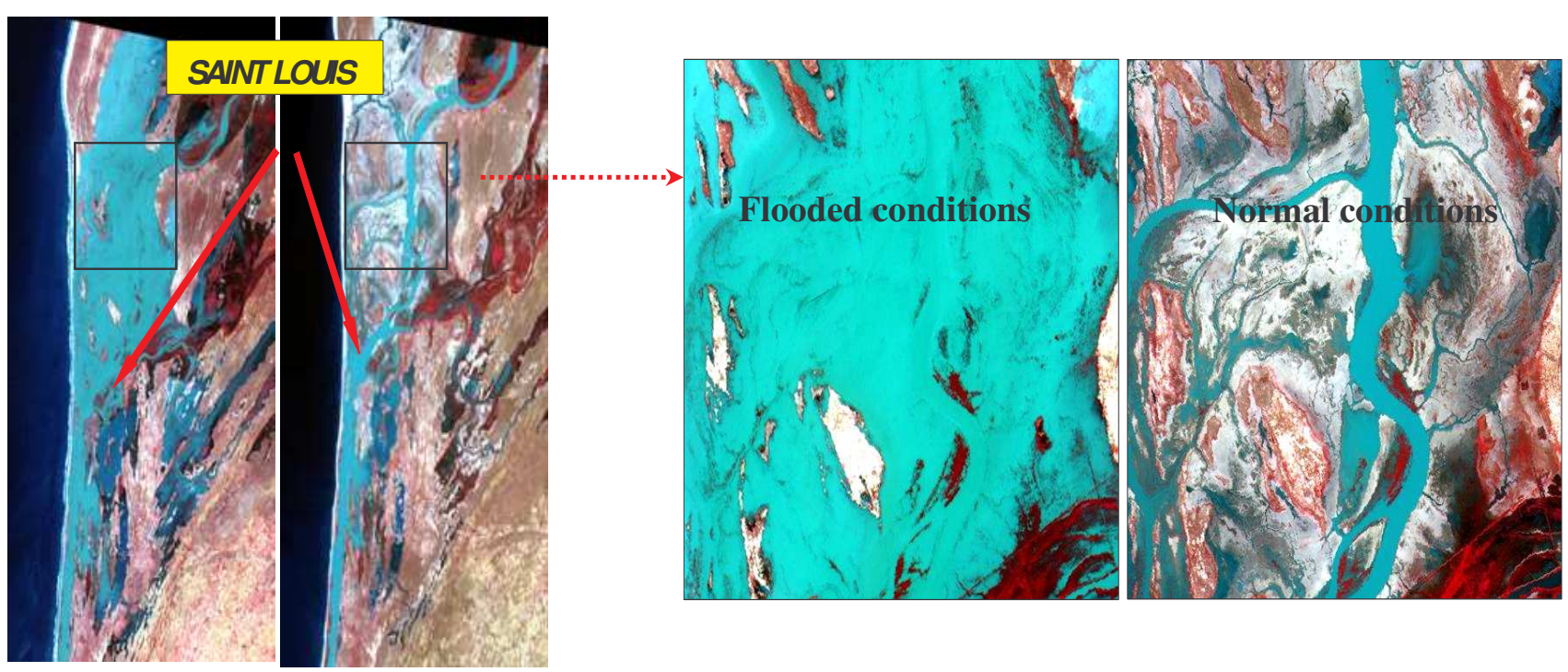

Figure 4: Satellite Imagery of Senegal River Lower Estuary, Flood conditions in October 1999 (left) and no flood conditions in October 2001 (right)

The impacts of the floods were severe because of the high levels of vulnerability and low levels of resilience of the population, the lack of adequate physical protection infrastructure and changing flood patterns due to environmental change as well as the impact of the Diama dam's structures. Man-made factors contributed to the seriousness of the event. The increasing occupation of floodplains around the city of Saint Louis in the estuary, competing and conflicting developmental demands in the lower Senegal river valley have exacerbated the impacts of floods on society (Dia, 2004). Even though the floods are obviously a fact of nature, their impacts on local resident depend on a large scale on the behaviour of the population. 


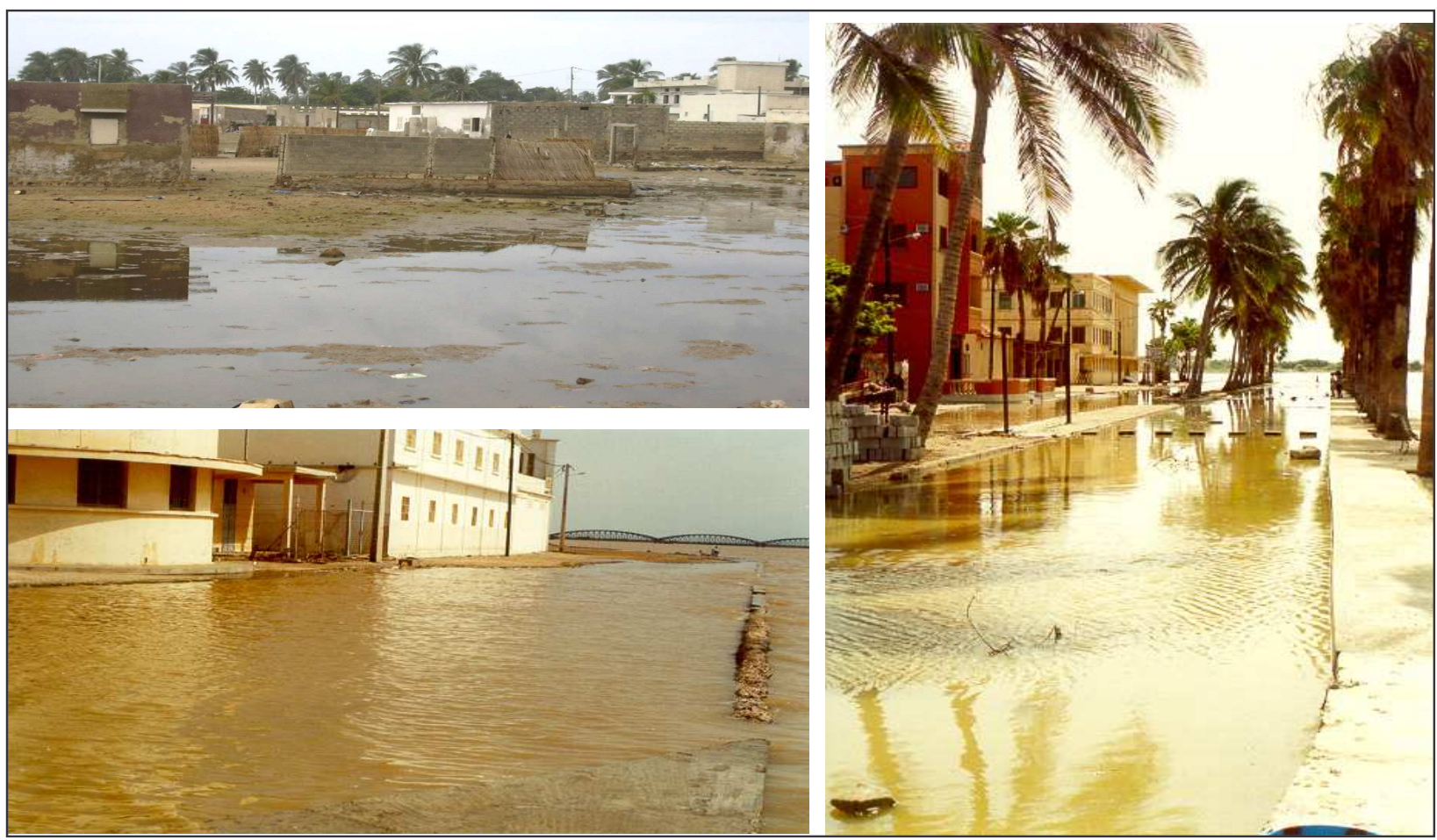

Figure 5: A view of flooded area in Saint-Louis in 1999

\section{Methodology of flood map extraction}

An approach based on satellite images, such as the one used here, has previously been used by Sandholt et al. (2003) in the lower valley around the city of Podor. This pilot study focused on different Landsat satellite images in combination with data from other sensors like Advanced Very High Resolution Radiometer (AVHRR) and radar data from European Remote Sensing Satellites (ERS).

\section{Geometric correction}

The SPOT Landsat satellite images used in this research were not directly georefenced which lead to deformations. This meant that they had to be oriented in order to ensure conformity with the geographic reality. All the images have been geometrically rectified to UTM Zone 28 North.

\section{Image fusion}

In this case of images fusion, the researchers combined the spatial information of the high resolution panchromatic image of 16 January, 2001 (10 meter of resolution), with the multispectral SPOT images of 23, October, 1999 and of 31 October, 2002 (20 meter of resolution). This permitted a richer image to be obtained simultaneously 
in spatial and spectral information. The fusion is most certainly an important manipulation to realize in the case of such a study, but we realise that the panchromatic image brings noise on the Spot XS image and this information is very difficult to analyse in the classification process.

\section{The classification process}

A standard supervised maximum likelihood classification was carried out using the ENVI (environment for visualizing images) image processing system. A total of five spectrally different classes were identified corresponding to spectral variability in the image. Differences on water reflectance are caused by turbidity and water depth and presence of varying amounts of green vegetation. Training and test areas were defined using field observations and delimitation carried out from a visual interpretation of SPOT images.
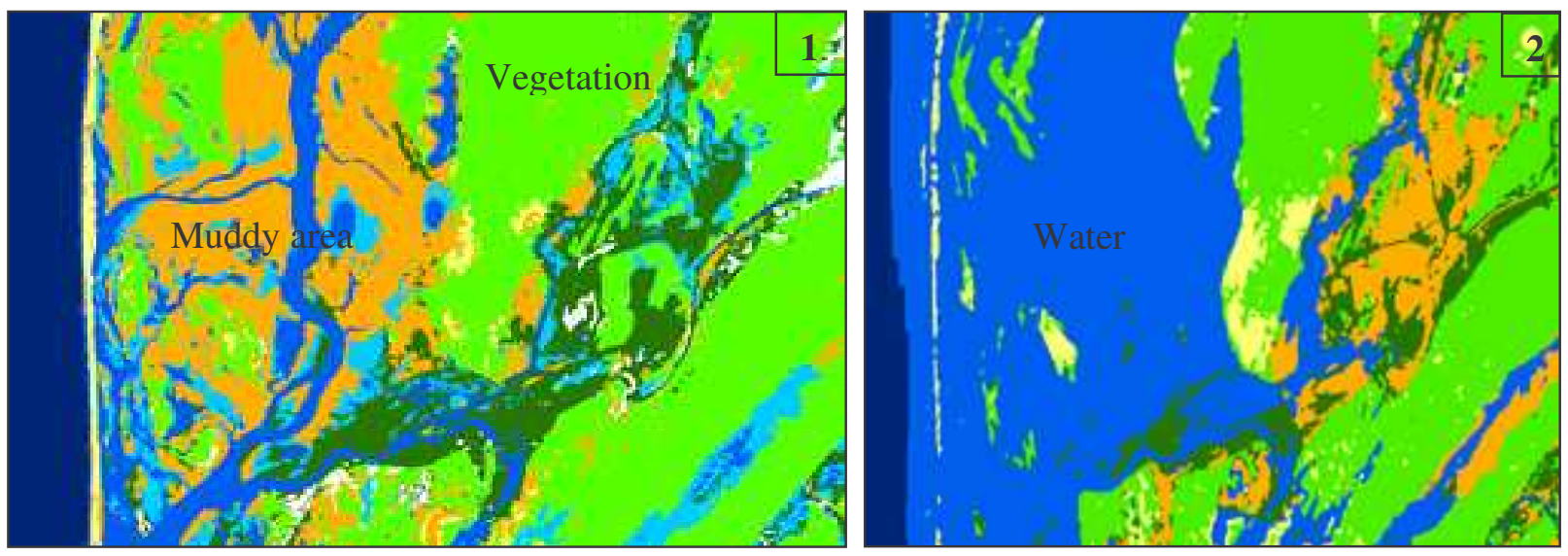

Figure 6: The classification results (1. Normal situation in 2001, 2. Flood situation in 1999)

\section{Cartography of flood extension in the estuary}

The cartography of flooded areas of the Senegal River estuary, permitted to isolate the different zones affected in October 1999. It is a multi-temporal approach which consists in comparing water surfaces around the city of Saint-Louis between the flooded period (SPOT 23/10/1999) and the normal period (SPOT 31/10/2001). The river bed largely overflowed and all the regions in the north of the town of Saint-Louis were considerably flooded. 


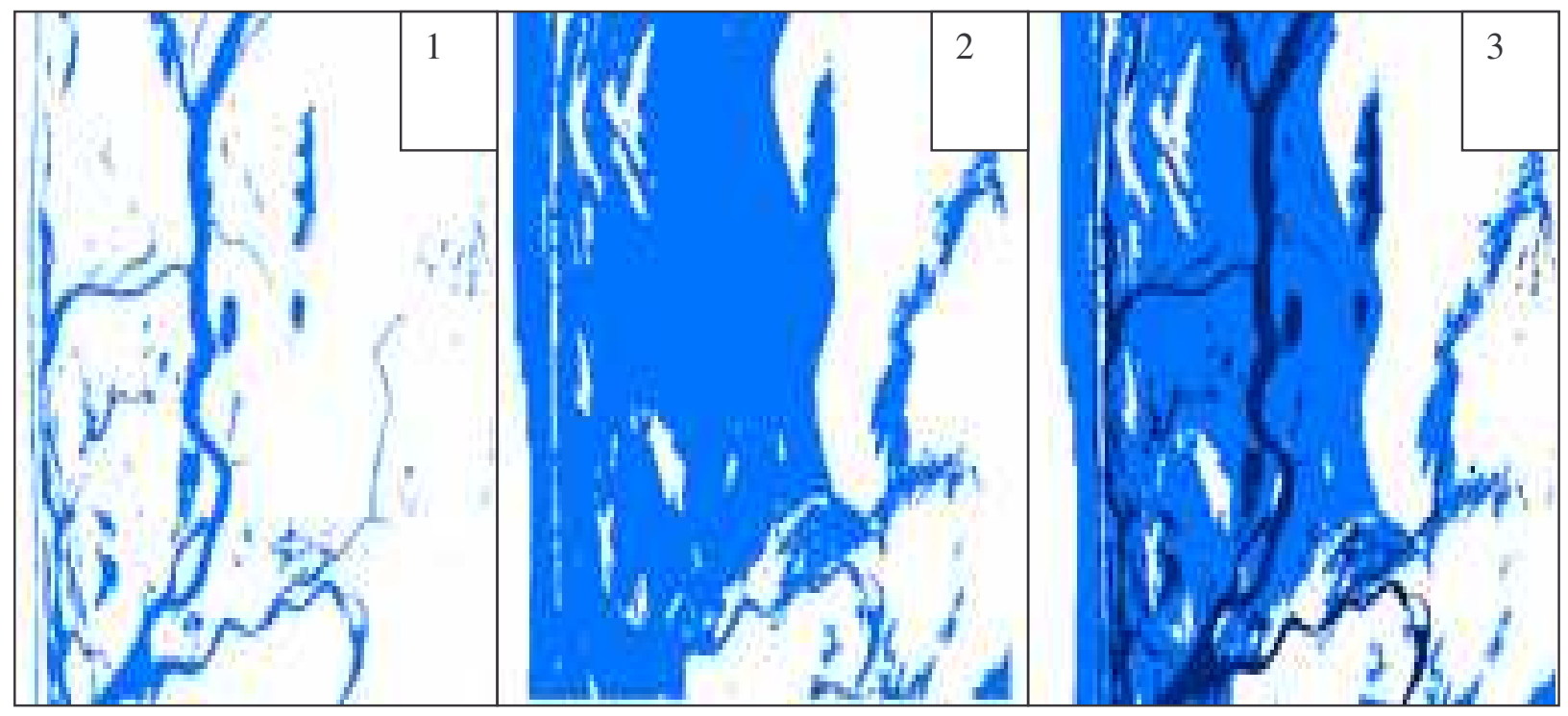

Figure 7: Flood extension in 1999

(1. Normal situation in 2001. 2. Flood situation in 1999, 3. Comparison of the 2 periods)

The flood map referred to here (figure 7) is a map that graphically provides information on the extension of inundation in an easy-to-understand format. The goal is to show the high level of vulnerability of many areas around the city of Saint-Louis to practitioners active in disaster risk reduction and those in charge of rivers and hydrology at local and regional level. The flood hazard map is particularly handy for planners and administrators in formulating remedial strategies. It also makes the process of resource allocation simple, resulting in a smooth and effective implementation of the adopted flood management strategy.

\section{Conclusion}

The research involved field work and the collection information and data about the floods and the use of Geographic Information Systems (GIS). The investigations provided insights on the overall organisation of the study zone, in particular on the occupation of the easily flooded area around the town of Saint-Louis and some villages and small towns in the lower valley. The investigations allowed researchers to define the limit of the extension of the past floods and to index the level of the various historical risings. In this study the issue of flood hazard mapping has been addressed from the perspective of different mapping scales in a GIS environment. The flood hazard map is particularly handy for planners and administrators for formulating remedial strategies. 
It also makes the process of resource allocation simple resulting in a smooth and effective implementation of the adopted flood management strategy. The aim of this regional study was to broadly identify the high hazard area in the area around the city of Saint-Louis and in the lower estuary of the Senegal River valley. Our project eventually led to the identification of a high hazard zone. 


\section{References}

CODATA. 2002. Scientific Data for decision making toward sustainable development Senegal River Basin: Case Study. Workshop, 11-15 March, 2002, Dakar, Senegal.

DIA, A. M. 2004. Flood-prone coastal town promotes culture of risk. Disaster Reduction in Africa, ISDR Forms, Issue 3.

DIA, A. M. 2004. Earth observation based flood monitoring in the Senegal River valley and estuary. In Global Symposium for hazard risk reduction. Lessons Learned from the Applied Research Grant for disaster risk reduction program. ProVention Consortium, World Bank, Washington DC.

GIACOMELLI, A., MANCINI, M., AND ROSSO, R. 1998. Integration of ERS-1 PRI imagery and digital terrain models for the assessment of flooded areas. In The 3rd ERS Symposium (ESA) 18-21 March 1997 Florence (Italy).

GILIF 2002. Gestion intégrée du littoral et du bassin fluvial du Sénégal, Rapport final, 2002

IRD, 2001. Programme d'Optimisation des Reservoires. Rapport préliminaire.

SANDHOLT, I., FOG, B. \& FENSHOLT, R. 2001. Flood monitoring in the Senegal River valley: First results based on SAR PRI data. To appear in Proceedings of ERS - ENVISAT SYMPOSIUM "Looking down to Earth in the New Millennium" GOTHENBURG, 16 - 20 October 2000. ESA.

SANDHOLT INGE, NYBORG, LOTTE, FOG BJARNE, LÔ MÉDOU, BOCOUM OUSMANE \& RASMUSSEN KJELD 2003. Remote Sensing Techniques for Flood Monitoring in the Senegal River Valley. Geografisk Tidsskrift, Danish Journal of Geography 103(1).

LAYGUER, O., FELLAH, K., .THOLEY, N., MEYER, C., AND DE FRAIPONT, P. 1998. High temporal detection and monitoring of flood zone dynamic using ERS data around catastrophic natural events: the 1993 and 1994 Camargue flood events. In The $3^{\text {rd }}$ ERS Symposium (ESA) 18-21 March 1997 Florence (Italy). 
${ }^{1}$ Institut de Recherche pour le Développement
${ }^{2}$ Gestion Intégrée du Littoral et du Bassin Fluvial 